\title{
Improvement of Cutting Tool Life by AIN Deposition on the Tool
}

\author{
Hiroshi YAGUCHI, Katsuhiko OZAKI ${ }^{1)}$ and Masami SOMEKAWA ${ }^{2)}$ \\ Materials Research Labs., Kobe Steel, Ltd., 1-5-5 Takatsukadai, Nishi, Kobe 651-2271 Japan. \\ 1) Mechanical Research Labs., Kobe Steel, Ltd., 1-5-5 Takatsukadai, Nishi, Kobe 651-2271 Japan. \\ 2) Kobe Works, Kobe Steel, Ltd., 2 Nadahama-Higashi, Nada, Kobe 657-0863 Japan.
}

(Received on January 21, 2003; accepted in final form on October 16, 2003)

\begin{abstract}
SCM415 steel was machined with carbide tools in as hot rolled condition and after normalizing heat treatment. In the as-rolled sample, a significant amount of Al and N existed as solid solution; whereas, in the normalized sample, $\mathrm{Al}$ and $\mathrm{N}$ existed as AIN precipitates. Reduction of tool wear for the as-rolled sample was observed. On the rake face of the tool machined for the as-rolled sample, the presence of AIN deposit was observed. It is believed that $\mathrm{Al}$ and $\mathrm{N}$ in solid solution form AIN deposit on the tool face due to temperature rise during machining, and that the deposition of the AIN layer on the tool face prevents diffusion between the tool and chip and reduces tool wear.
\end{abstract}

KEY WORDS: free-machining steel; AIN; machinability; tool life.

\section{Introduction}

It is known that carbide cutting tool life is improved when machining is carried out with steels deoxidized with Ca. ${ }^{1-3)}$ Protecting layer of oxides and sulfides, so called "belag" is formed on tool face to protect tools from wear. It has been reported that protective layer is not limited to belag of oxides and sulfides, but nitrides can also form protective layer. The first nitride deposit reported to form protective layer was boron-nitride or BN. ${ }^{4-6)}$ Nextly, deposition of AlN on the tool was reported to form for the samples containing BN. ${ }^{7-11)}$ Further, it was recently reported that the deposition of AlN can take place with the steels even without $\mathrm{BN}$ addition. ${ }^{11,12)}$ The deposition of $\mathrm{VN}$ can also be formed. ${ }^{13)}$

These observations suggest a possibility of a new type of free-machining steel. Thus, investigation was initiated to clarify the condition of AlN deposition. It is assumed that, if $\mathrm{Al}$ and $\mathrm{N}$ exist as solid solution in steel, AlN deposit could be formed on the cutting tool during machining due to temperature rise.

\section{Experimental Procedure}

Industrially made Al-killed JIS SCM415 steel was selected, and hot rolled to $60 \mathrm{~mm}$ diameter bar in the industrial bar rolling mill. The chemical composition was $0.17 \% \mathrm{C}$, $0.19 \% \mathrm{Si}, 0.72 \% \mathrm{Mn}, 0.016 \% \mathrm{~S}, 1.05 \% \mathrm{Cr}, 0.23 \% \mathrm{Mo}$, $0.024 \% \mathrm{Al}, 0.0106 \% \mathrm{~N}$. No special de-oxidation practice was utilized. The as-rolled sample and the sample normalized at $900^{\circ} \mathrm{C} \times 2 \mathrm{~h}$ after rolling were investigated. It is expected that, in the as-rolled sample a significant amount of $\mathrm{Al}$ and $\mathrm{N}$ exist as solid solution, and in the normalized sample, most of $\mathrm{Al}$ and $\mathrm{N}$ exist as $\mathrm{AlN}$ precipitates and the amount of $\mathrm{Al}$ and $\mathrm{N}$ in solid solution is small. According to equilibrium thermodynamic calculation, at $900^{\circ} \mathrm{C}$, approximately $80 \%$ of $\mathrm{Al}$ is combined as AlN.

Turning experiments with P10 carbide tools was carried out as machining test under dry condition, with cutting speed of $200 \mathrm{~m} / \mathrm{min}$, feed of $0.25 \mathrm{~mm} / \mathrm{rev}$ and depth of cut $1.5 \mathrm{~mm}$. Tool wear on both rake face and flank face was measured at certain machining periods

\section{Results and Discussion}

Figure 1 shows typical microstructure of the as-rolled and normalized samples. The as-rolled sample has ferritebainite microstructure and hardness of HV166. The normalized sample has ferrite-pearlite microstructure and hardness of HV138. Figure 2 shows a typical oxide inclusion observed. Oxides are $\mathrm{Al}_{2} \mathrm{O}_{3}$ or spinel type containing $\mathrm{Mg}$ which is believed to come from refractory. Sulfide inclusions were the typical elongated type.

Figures 3 and 4 show crater wear and flank wear measurement results, respectively. Significant reduction of crater wear for the as-rolled sample is observed in spite of higher hardness. Flank wear for the as-rolled sample is also small.

Figures 5 and $\mathbf{6}$ show X-ray mapping in EPMA on crater tool faces for the as-rolled and normalized samples. For the as-rolled sample (Fig. 5), Al and $\mathrm{N}$ are clearly detected on the same area of worn tool face. On the other hand, the presence of belag or deposit of oxides and sulfides is not observed on the worn area. Figure 7 shows small size Xray diffraction analysis on the area where both $\mathrm{Al}$ and $\mathrm{N}$ are observed. The presence of AlN is suggested. Arrows on the top of the figure indicate the peaks of AlN. As shown in Fig. 6, weak $\mathrm{Al}$ and $\mathrm{N}$ are also observed for the normalized sample. However, as shown in Fig. 8, the presence of AIN is not confirmed for the normalized sample by X-ray dif- 


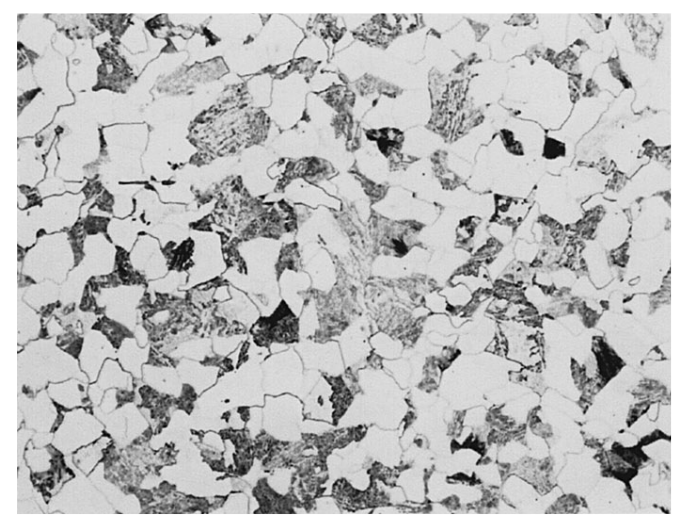

As-rolled

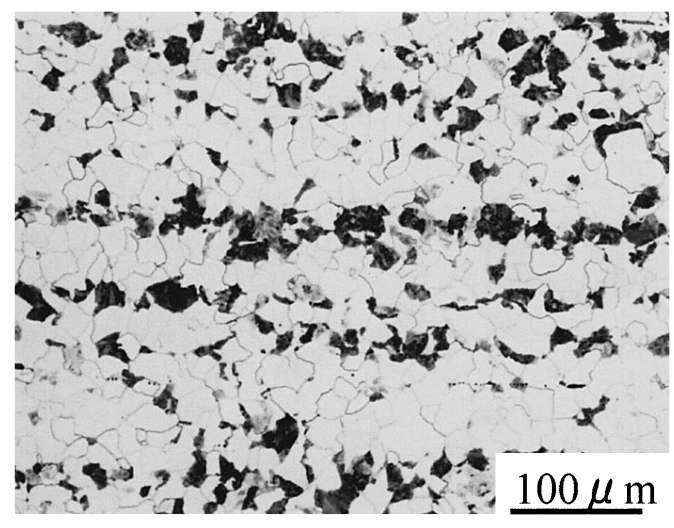

Normalized

Fig. 1. Microstructure of the samples.
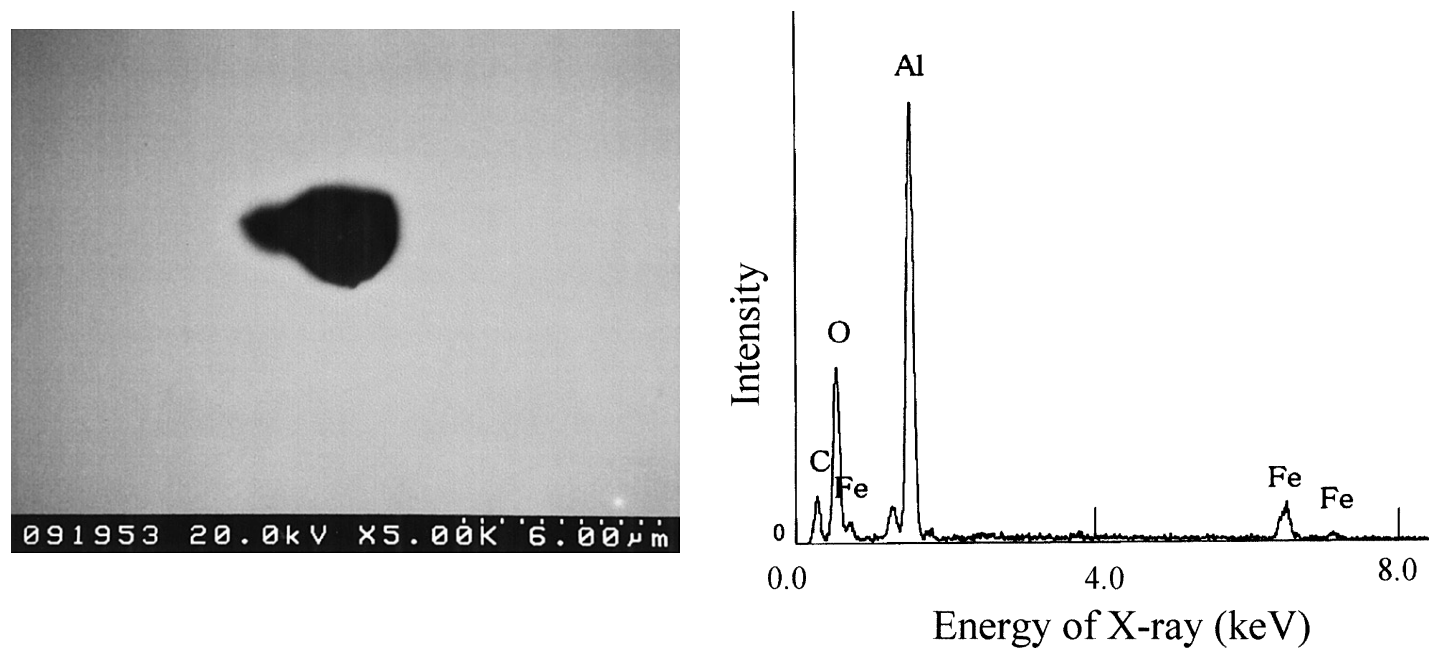

Fig. 2. Typical $\mathrm{Al}_{2} \mathrm{O}_{3}$ type oxide inclusion observed.

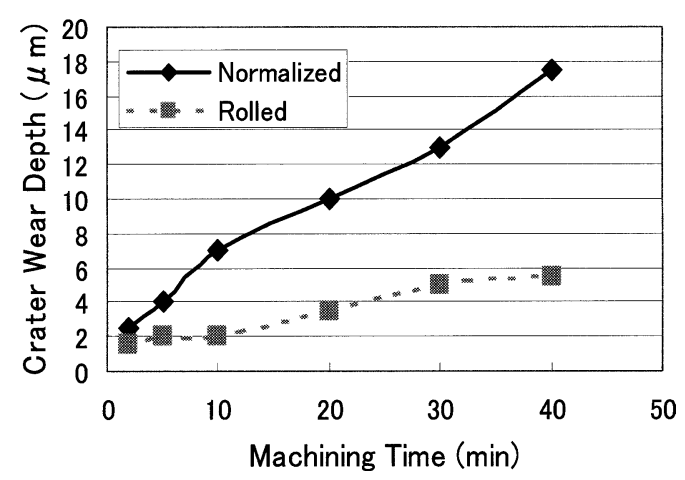

Fig. 3. Crater wear measurement results.

fraction.

In order to investigate the origin of AlN deposit on the tool, chemical analysis was carried out to measure not only total $\mathrm{Al}$ and $\mathrm{N}$ but also $\mathrm{Al}$ and $\mathrm{N}$ in solid solution. $\mathrm{Al}$ and $\mathrm{N}$ in solid solution were analyzed by the following method. The details of analyzing method are summarized in Table 1.

$$
\begin{aligned}
& \mathrm{Al}(\text { solution })=\mathrm{Al}(\text { total })-\mathrm{Al} \text { as } \mathrm{Al}_{2} \mathrm{O}_{3}-\mathrm{Al} \text { as } \mathrm{AlN} \\
& \mathrm{N}(\text { solution })=\mathrm{N}(\text { total })-\mathrm{N}(\text { combined })
\end{aligned}
$$

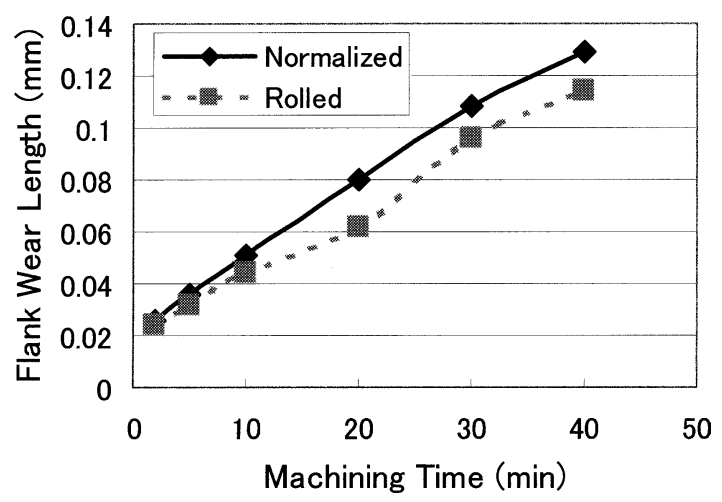

Fig. 4. Flank wear measurement results.

Table 2 shows the analyzed results of $\mathrm{Al}$ and $\mathrm{N}$ in solid solution. It is clearly shown that the as-rolled sample, which had smaller tool wear contains higher amount of $\mathrm{Al}$ and $\mathrm{N}$ in solid solution. This clarifies that $\mathrm{Al}$ and $\mathrm{N}$ were dissolved during hot rolling. During following normalizing heat treatment, $\mathrm{Al}$ and $\mathrm{N}$ in solid solution were combined to AlN as suggested by thermo-dynamical estimation.

Due to heavy and rapid deformation during machining, significant localized heat generation takes place. It has been reported that the maximum temperature in the tool-chip in- 


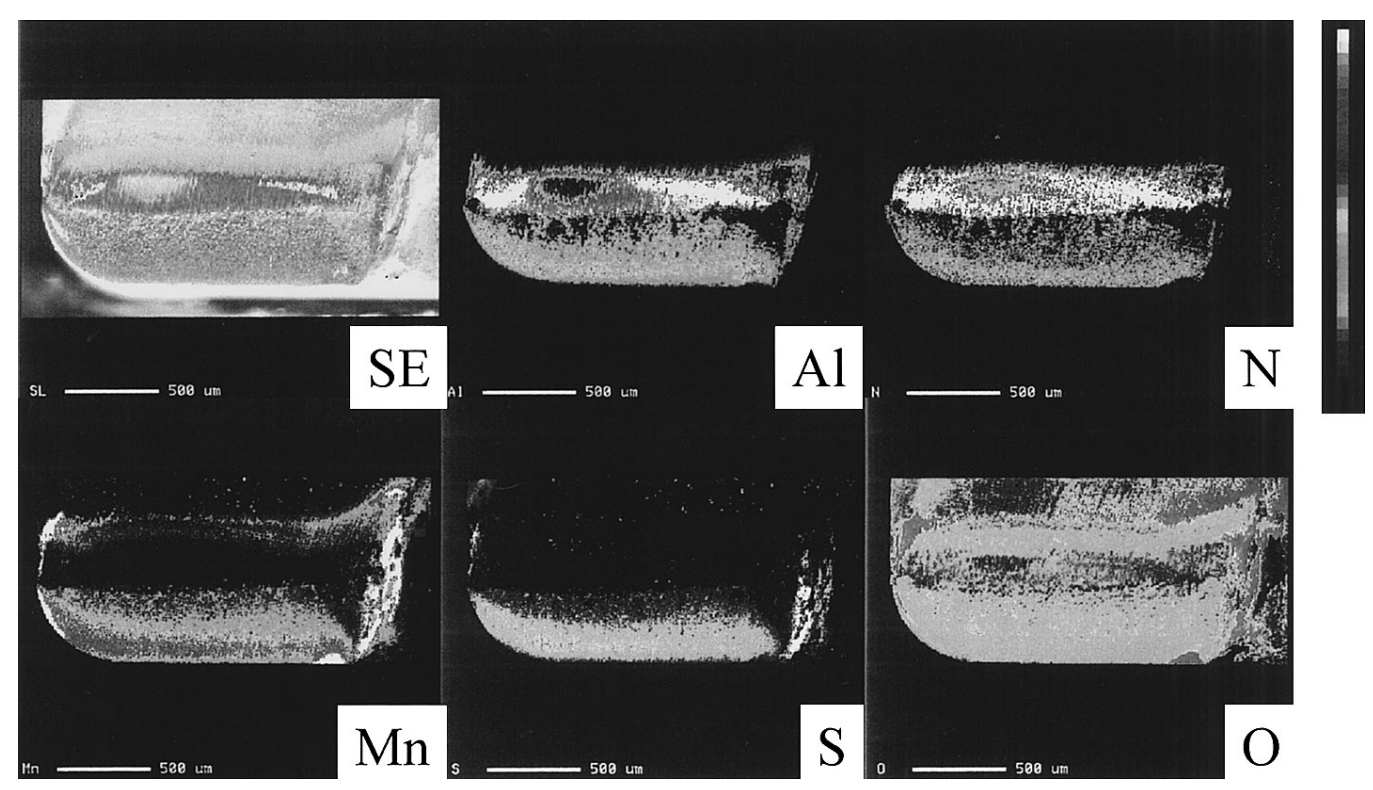

Fig. 5. X-ray mapping in the EPMA of the rake face of the tool used for the as-rolled sample.

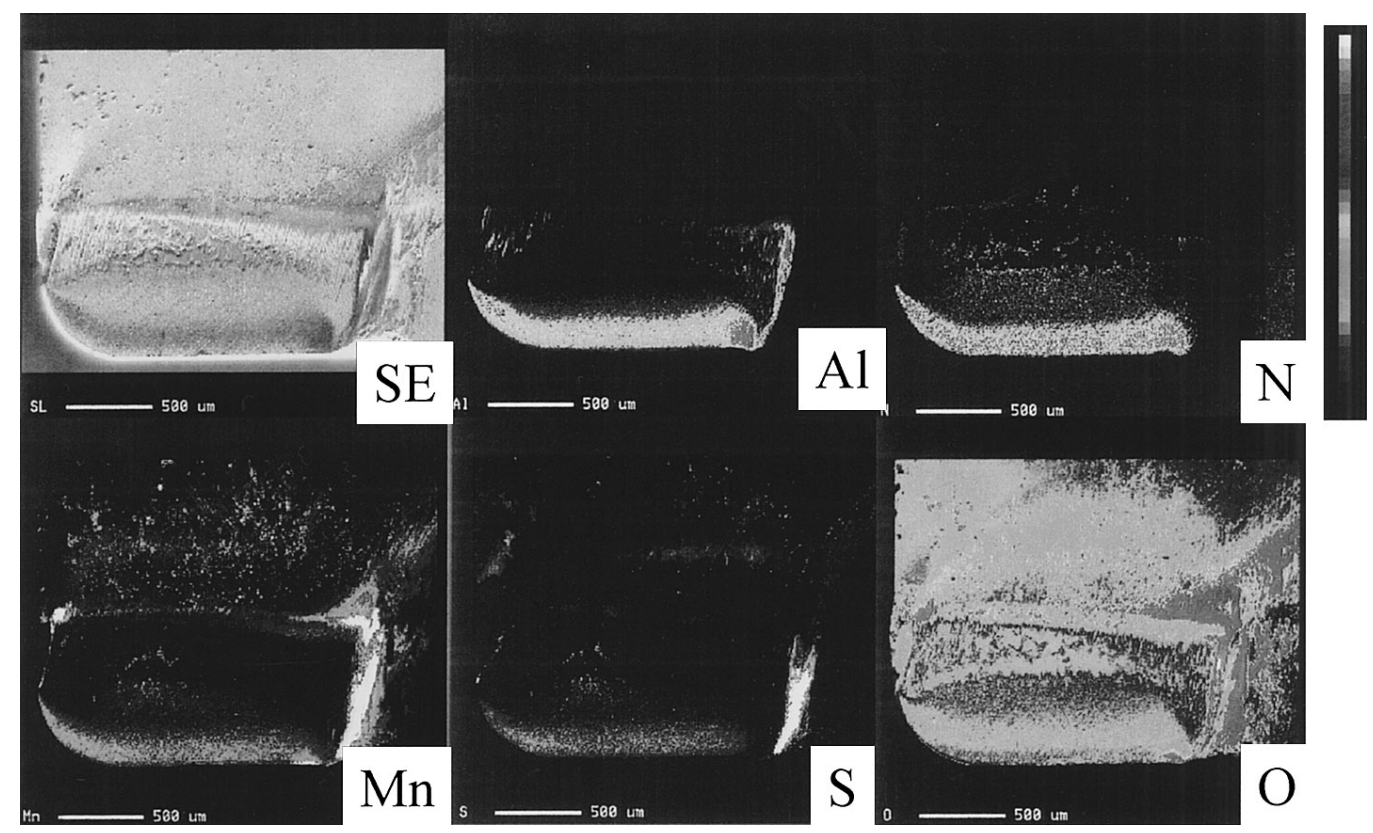

Fig. 6. X-ray mapping in the EPMA of the rake face of the tool used for the normalized sample.

terface reaches $1000^{\circ} \mathrm{C}$ or higher for the cutting conditions similar to the condition used in this investigation. ${ }^{14,15)}$ Thus, it is reasonable to believe that the soluble $\mathrm{Al}$ and $\mathrm{N}$ in the steel combine at the tool-chip interface as AlN due to temperature rise and deposit on the tool surface. Since it has been reported that the presence of AIN layer prohibits diffusion between tool and chip, ${ }^{10)}$ tool wear is reduced by the presence of AlN deposited layer.

\section{Conclusions}

Low carbon low alloy steel (SCM415) was machined with carbide tools in as hot rolled condition and after nor- malizing heat treatment. The following conclusions are obtained:

(1) The as-hot rolled sample, which contains significant amount of $\mathrm{Al}$ and $\mathrm{N}$ as solid solution showed smaller tool wear compared with the normalized sample, in which $\mathrm{Al}$ and $\mathrm{N}$ existed as AlN precipitates.

(2) On the rake face of the tool machined for the asrolled sample, presence of AlN was observed. It is believed that $\mathrm{Al}$ and $\mathrm{N}$ in solid solution form $\mathrm{AlN}$ deposit on the tool face due to temperature rise during machining.

(3) It is suggested that the deposition of the AIN layer on the tool face prevents diffusion between the tool and chip and reduces tool wear. 


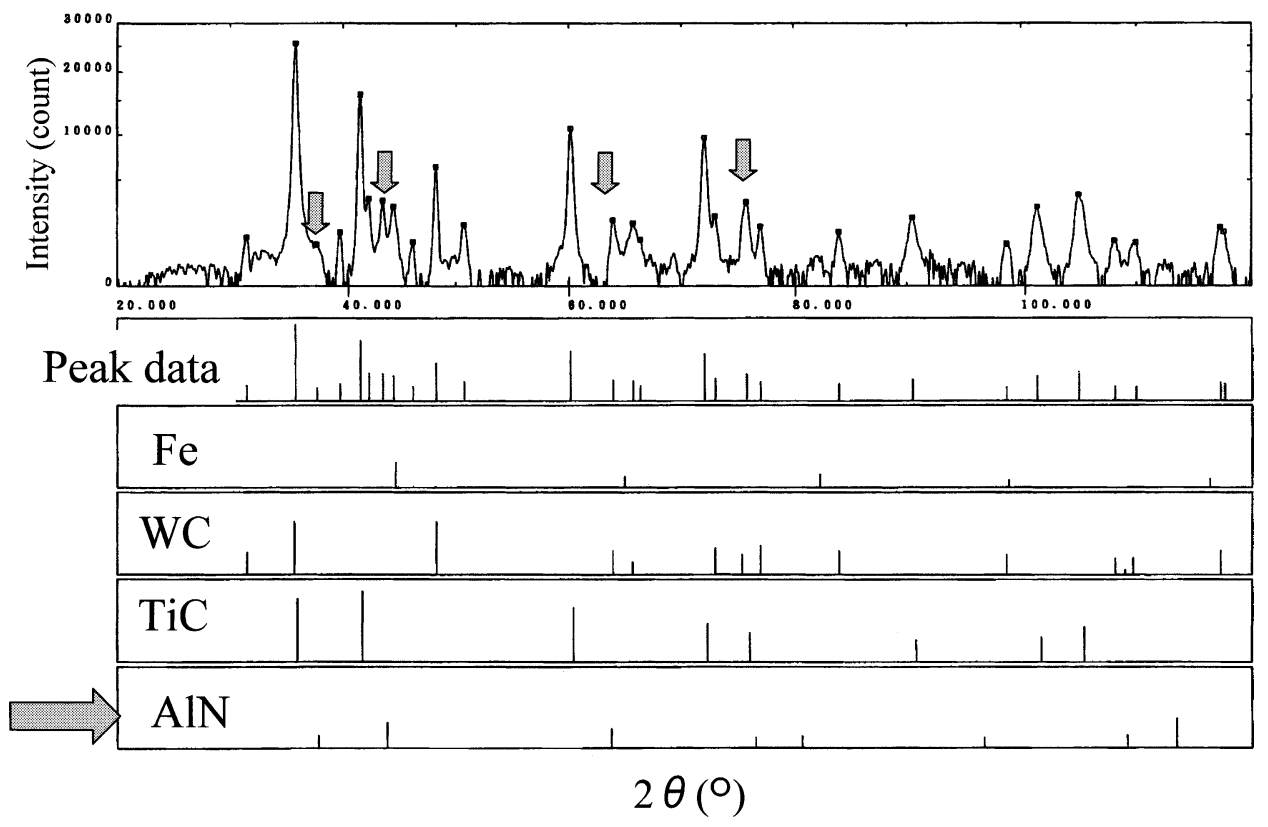

Fig. 7. X-ray diffraction analysis on the rake face of the tool used for the as-rolled sample. The $\mathrm{X}$-ray was $\mathrm{Cu}-\mathrm{K} \alpha$, and the beam size $50 \mu \mathrm{m}$.
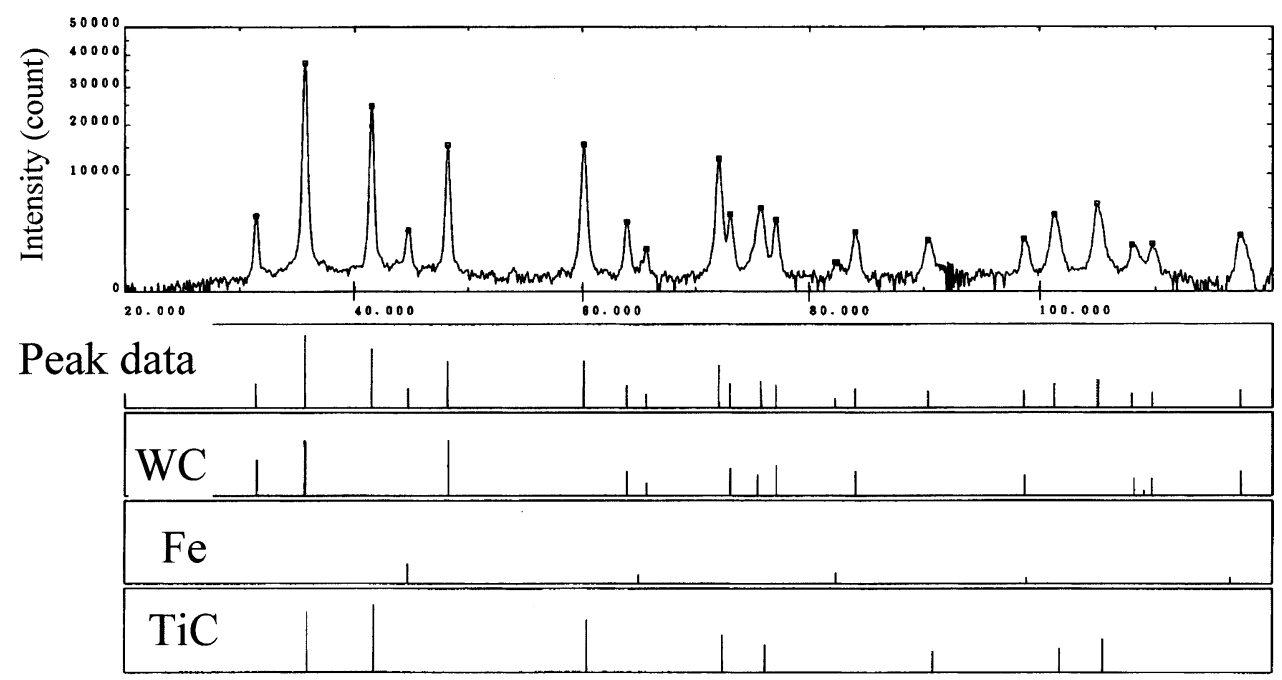

\section{$2 \theta\left({ }^{\circ}\right)$}

Fig. 8. X-ray diffraction analysis on the rake face of the tool used for the normalized sample. The $\mathrm{X}$-ray was $\mathrm{Cu}-\mathrm{K} \alpha$, and the beam size $50 \mu \mathrm{m}$.

Table 1. Method to analyze $\mathrm{Al}$ and $\mathrm{N}$ in solid solution.

$\mathrm{Al}($ solution $)=\mathrm{Al}$ (total) $-\mathrm{Al}$ as $\mathrm{Al}_{2} \mathrm{O}_{3}-\mathrm{Al}$ as $\mathrm{AlN}$

$\mathrm{N}($ solution $)=\mathrm{N}($ total $)-\mathrm{N}($ combined $)$

\begin{tabular}{|c|l|}
\hline Analysis & \multicolumn{1}{c|}{ Method } \\
\hline $\mathrm{Al}$ (total) & ICP-AES (Inductively Coupled Plasma Atomic Emission Spectroscopy) \\
\hline $\mathrm{Al}_{2} \mathrm{O}_{3}$ & $10 \%$ Bromine - methanol extraction $\rightarrow$ ICP-AES \\
\hline $\mathrm{AlN}$ & Bromine-methyl acetate extraction $\rightarrow$ Distillation separation titrimetry \\
\hline $\mathrm{N}($ total $)$ & Inert gas fusion thermal conductivity method \\
\hline $\mathrm{N}($ combined) & $\begin{array}{l}\text { Electrolytic extraction } \rightarrow \text { Colorimetry } \\
\text { Solution : 10\%Acetylacetone }-1 \% \text { Tetramethylammonium chroride } \\
\text { methanol }\end{array}$ \\
\hline
\end{tabular}

Table 2. Analyzed $\mathrm{Al}$ and $\mathrm{N}$ in solid solution (mass\%).

\begin{tabular}{|c|c|c|c|c|c|c|c|}
\hline Sample & $\mathrm{Al}$ (total) & $\mathrm{Al}_{2} \mathrm{O}_{3}$ & $\mathrm{AlN}$ & $\mathrm{Al}$ (solution) & $\mathrm{N}$ (total) & $\mathrm{N}$ (combined) & $\mathrm{N}$ (solution) \\
\hline As-rolled & 0.023 & 0.0042 & 0.0017 & 0.020 & 0.011 & 0.0017 & 0.0093 \\
\hline Normalized & 0.023 & 0.0076 & 0.021 & 0.005 & 0.011 & 0.0077 & 0.0033 \\
\hline
\end{tabular}


ISIJ International, Vol. 44 (2004), No. 3

\section{REFERENCES}

1) H. Opitz and W. Konig: Iron Steel Inst. Spec. Rep., 94 (1964), 35.

2) Y. Yamane, H. Usuki, B. Yan and N. Narutaki: Wear, 139 (1990), 195.

3) Y. Yamane: Proc. Tribology Metal Cutting Grinding, (1992), 53.

4) T. Hanyuda and S. Nakamura: Denki Seiko, 65 (1993), 4.

5) H. Katayama, I. Asano and M. Hashimura: CAMP-ISIJ, 5 (1992), 847.

6) H. Yaguchi: CAMP-ISIJ, 7 (1994), 770.

7) T. Shiraga and Y. Yamane: CAMP-ISIJ, 12 (1999), 475.

8) T. Shiraga and Y. Yamane: CAMP-ISIJ, 13 (2000), 532.
9) Y. Yamane, R. Tanaka and N. Narutaki: J. Precision Eng., 64 (1998), 1370 .

10) Y. Yamane, R. Tanaka, K. Sekiya, N. Narutaki and T. Shiraga: $J$. Precision Eng., 66 (2000), 229.

11) Y. Yamane, R. Tanaka, K. Sekiya, N. Narutaki and T. Shiraga: $J$. Precision Eng., 68 (2002), 705.

12) N. Tsunekage, K. Kobayashi and H. Tsubakino: Proc. Int. Conf. on Steel and Society (ICSS 2000), ISIJ, Tokyo, (2000), 299.

13) S. Ohwaki: Heat Treat., 42 (2002), 42.

14) T. Kurimoto and G. Barrow: Ann. CIRP, 31 (1982), 19.

15) E. F. Smart and E. M. Trent: Int. J. Prod. Res., 13 (1975), 265. 